\title{
In-Depth Proteomic Characterization of Classical and Non-Classical Monocyte Subsets
}

\author{
Víctor Segura ${ }^{1}$, M. Luz Valero ${ }^{2}$ (i), Laura Cantero ${ }^{2}$, Javier Muñoz ${ }^{3}$, Eduardo Zarzuela ${ }^{3}$, \\ Fernando García ${ }^{3}$ (i), Kerman Aloria ${ }^{4}$, Javier Beaskoetxea ${ }^{5}$, Jesús M. Arizmendi ${ }^{5}$, \\ Rosana Navajas ${ }^{6}$ (D), Alberto Paradela ${ }^{6}$ (D), Paula Díez ${ }^{7,8}$, Rosa $M^{a}$ Dégano ${ }^{7,8}$, \\ Manuel Fuentes 7,8 (D), Alberto Orfao ${ }^{9}$, Andrés García Montero ${ }^{10}$, Alba Garin-Muga ${ }^{1}$, \\ Fernando J. Corrales ${ }^{6}$ and Manuel M. Sánchez del Pino 11,12,* (D) \\ 1 Proteomics, Genomics and Bioinformatics Unit, Center for Applied Medical Research, University of Navarra, \\ Pamplona 31008, Spain; vsegura@unav.es (V.S.); agarin@unav.es (A.G.-M.) \\ 2 Proteomics Unit; Central Service for Experimental Research (SCSIE), University of Valencia. Dr Moliner 50, \\ 46100 Burjassot, Spain; mluz.valero@uv.es (M.L.V.); laura.cantero@uv.es (L.C.) \\ 3 Spanish National Cancer Research Centre (CNIO), Melchor Férnandez Almagro, 3, 28029 Madrid. Spain; \\ jmunozpe@cnio.es (J.M.); ezarzuela@cnio.es (E.Z.); fgarcia@cnio.es (F.G.) \\ 4 Proteomics Core Facility-SGIKER, University of the Basque Country, UPV/EHU, 48940 Leioa, Spain; \\ kerman.aloria@ehu.eus (K.A.) \\ 5 Department of Biochemistry and Molecular Biology, University of the Basque Country, UPV/EHU, \\ 48940 Leioa, Spain; javier.beaskoetxea@ehu.eus (J.B.); jm.arizmendi@ehu.eus (J.M.A.) \\ 6 Proteomics Unit, Centro Nacional de Biotecnología-CSIC, Darwin 3, 28049 Madrid, Spain; \\ rnavajas@cnb.csic.es (R.N.); alberto.paradela@cnb.csic.es (A.P.); fcorrales@cnb.csic.es (F.J.C.) \\ 7 Department of Medicine and General Cytometry Service-Nucleus, Cancer Research \\ Centre (IBMCC/CSIC/USAL/IBSAL), 37007 Salamanca, Spain; pauladg@usal.es (P.D.); \\ romade@usal.es (R.M ${ }^{\mathrm{a}}$.D.); mfuentes@usal.es (M.F.) \\ 8 Proteomics Unit. Cancer Research Centre (IBMCC/CSIC/USAL/IBSAL), 37007 Salamanca, Spain \\ 9 Cancer Research Center. University of Salamanca-CSIC, IBSAL, 37007 Salamanca, Spain; \\ orfao@usal.es (A.O.) \\ 10 Spanish National DNA Bank Carlos III, University of Salamanca, 37007 Salamanca, Spain; \\ angarmon@usal.es (A.G.M.) \\ 11 Department of Biochemistry and Molecular Biology, University of Valencia. Dr Moliner 50, 46100 Burjassot, Spain \\ 12 Biotechnology and Biomedicine Interdisciplinary Research Unit (ERI BIOTECMED), University of Valencia. \\ Dr Moliner 50, 46100 Burjassot, Spain \\ * Correspondence: sandelpi@uv.es; Tel.: +34-96-354-3464
}

Received: 7 December 2017; Accepted: 1 February 2018; Published: 5 February 2018

\begin{abstract}
Monocytes are bone marrow-derived leukocytes that are part of the innate immune system. Monocytes are divided into three subsets: classical, intermediate and non-classical, which can be differentiated by their expression of some surface antigens, mainly CD14 and CD16. These cells are key players in the inflammation process underlying the mechanism of many diseases. Thus, the molecular characterization of these cells may provide very useful information for understanding their biology in health and disease. We performed a multicentric proteomic study with pure classical and non-classical populations derived from 12 healthy donors. The robust workflow used provided reproducible results among the five participating laboratories. Over 5000 proteins were identified, and about half of them were quantified using a spectral counting approach. The results represent the protein abundance catalogue of pure classical and enriched non-classical blood peripheral monocytes, and could serve as a reference dataset of the healthy population. The functional analysis of the differences between cell subsets supports the consensus roles assigned to human monocytes.
\end{abstract}

Keywords: monocytes; protein profiling; quantitative proteomics 


\section{Introduction}

Monocytes are bone marrow-derived leukocytes with functional capacities including phagocytose, antigen presentation and cytokine production [1]. It was in the late 1980s that Passlik et al. identified different monocyte subsets based on the expression of the surface antigen CD16 [2]. Classical monocytes are critical components of innate immunity, represent the largest population of monocytes, lack CD16 antigen expression $\left(\mathrm{CD}_{14}{ }^{++} \mathrm{CD} 16^{-}\right)$, and are important scavenger cells [2,3]. Although there are contradictory results, it appears that non-classical monocytes produce more pro-inflammatory cytokines, including TNF $\alpha$ [4-6]. Non-classical monocytes appear to be mobilized in different disease scenarios [7,8], and have been considered as an inflammatory monocyte subset in humans. There is an additional monocyte subset called intermediate, which has been proposed as a transitional population bridging the classical and non-classical subsets [3,9]. The different functional properties of monocyte subsets have been widely studied and correlated with different pathogenic conditions. Hence, expansion of non-classical $\left(\mathrm{CD}_{16}{ }^{+}\right)$and, more consistently, intermediate populations in a wide array of inflammatory and infectious disorders (reviewed in [10,11]) led to the proposal that the definition of monocyte subset frequency could be considered as a biomarker with prognostic value [12]. However, whether $\mathrm{CD}_{16}{ }^{+}$monocytes play a protective or pathogenic role in different diseases is an issue that is still under discussion, and only a comprehensive phenotypic and functional characterization of the different subsets will allow the delineation of their specific association with either disease elimination or progression.

Genome wide gene expression analyses have been conducted to gain functional insights into classical, intermediate and non-classical monocyte subtypes $[6,13,14]$. Based on this molecular profiling, it has been proposed that classical monocytes are highly versatile cells that mediate anti-bacterial and inflammatory responses, and whose main function is phagocytosis. The non-classical subset, which is more active in $\mathrm{T}$ cell stimulation and proliferation, was distinguished by an up-regulation of cytoskeleton rearrangement genes, supporting a patrolling and infiltration function as well as inflammatory cytokine production $[6,14]$. The intermediate subset appears to be highly related to non-classical monocytes, and is considered to be a transitional subset between the classical and non-classical populations [3,15]. Intermediate monocytes have a pro-inflammatory function showing an enhanced MHCII processing and presentation activity over the non-classical subset $[10,11]$. Although the transcriptomic signatures have undoubtedly provided remarkable information to differentiate monocyte subsets, a complete biological and functional definition of their proteome under healthy conditions is needed to define the role of monocyte subsets in disease.

The Human Proteome Project (HPP) is an international initiative promoted by the Human Proteome Organization (HUPO) that was conceived in 2010 and launched over the subsequent two years [16,17]. The mission of the HPP is to systematically map and characterize the known proteins encoded by the approximately 20,000 protein coding genes of the human genome [17-19]. With the aim of providing a comprehensive map of human proteins in their biological context, the HPP rests on three technological pillars: the shotgun and targeted mass spectrometry pillar (MS), the affinity / antibodies-based pillar $(\mathrm{Ab})$, and an integrated knowledge-based resource. The overall project is organized according to a chromosome-centric strategy (C-HPP), whereby scientific groups from different nationalities agree to characterize the proteome of a selected chromosome following the guidelines of the international consortium and an open-access policy [19,20]. All 24 chromosomes plus the mitochondrial genome-encoded proteome have already been adopted by as many teams from 21 different countries. Knowledge and technical resources generated within the C-HPP initiative are expected to contribute to progress in the understanding and treatment of diseases by the integration and coordination of specific research initiatives through the Biology and Disease (BD)-HPP initiative [20]. Among the 23 BD initiatives currently active, recent developments in cancer proteomics have been summarized highlighting the impressive contribution that the mass spectrometry tool box is already making to reduce the global burden of this disease [21]. 
In this study, we provide an in-depth analysis of classical (CD14 $\left.{ }^{\text {high }} / \mathrm{CD}^{-} 6^{-}\right)$and non-classical (CD14-/low $/$ CD16 ${ }^{\text {high }}$ ) monocyte subsets from 12 healthy individuals. The robustness of the analysis is highlighted by the correlation of data resulting from the analyses performed in five independent laboratories. The protein abundance data provide a comprehensive molecular description of both monocyte populations that supports their functional characteristics. The findings reported here might provide valuable information to further understand the inflammatory process, to make progress in those BD-HPP initiatives focused on topics associated to inflammation, and also accounts for the identification of missing proteins, one of the challenges faced by the C-HPP.

\section{Materials and Methods}

\subsection{Subjects and Samples}

Fresh Anticoagulant Citrose Dextrate Solution A (ACD)-anticoagulated peripheral blood (PB) samples from 12 adult healthy volunteers (10 men and 2 women; median age of 45 years), were used for multiparameter flow cytometry isolation of both classical CD14 ${ }^{\text {high }} / \mathrm{CD} 16^{-}$and non-classical CD16 high $/ C D 14^{-/ \text {low }}$ monocyte subsets. Prior to entering the study, patients gave their written informed consent to participate according to the Declaration of Helsinki; the study protocol was approved by the External Ethical Committee of the Spanish National DNA Bank Carlos III (BNADN, University of Salamanca, Salamanca, Spain).

\subsection{Purification of PB Monocyte Subsets}

Isolation of both classical and non-classical PB monocyte subsets was performed within the first $24 \mathrm{~h}$ after sample collection using a 4-way fluorescence-activated cell-sorter (FACSAria III, Becton/Dickinson Biosciences -BDB-, San Jose, CA, USA), equipped with the FACSDiva software (BDB). Briefly, peripheral blood mononuclear cells (PBMC) were firstly isolated by a density-gradient centrifugation pre-enrichment step (Ficoll-Paque Plus, GE Healthcare Bio-Sciences AB, Uppsala, Sweden). The remaining erythrocytes were removed from the PBMC by an additional ammonium chloride-mediated red cell lysis step. Prior to sorting, cells were stained with a single 8-color combination of monoclonal antibodies-CD3/CD14/CD16/CD19/CD33/CD45/CD56/HLA-DR-(for details, Table 1), using a direct immunofluorescence flow cytometry technique according to well-established procedures. For PB monocyte subset isolation purposes, classical monocytes were identified as $\mathrm{CD} 14^{\text {high }} / \mathrm{CD}^{-} 6^{-} / \mathrm{CD} 33^{\text {high }} / \mathrm{HLA}^{-D R}{ }^{+} / \mathrm{CD} 45^{\text {high }} / \mathrm{CD} 3^{-} / \mathrm{CD} 19^{-} / \mathrm{CD}^{-} 6^{-}$cells, whereas non-classical PB monocytes were identified as $\mathrm{CD} 14^{-/ \text {low }} / \mathrm{CD} 16^{\text {high }} / \mathrm{CD} 33^{+/ \text {low }} / \mathrm{HLA}-\mathrm{DR}{ }^{\text {high }} / \mathrm{CD} 45^{\text {high }} /$ $\mathrm{CD}^{-} / \mathrm{CD}^{-} 9^{-} / \mathrm{CD}^{-} 6^{-}$cells [22]. The purity of each of the isolated PB monocyte population was analyzed with the Infinicyt ${ }^{\mathrm{TM}}$ software (Cytognos SL, Salamanca, Spain) and was $>98 \%$ for classical monocytes. Non-classical monocytes had an average contamination of $30 \%$ with intermediate monocytes.

Table 1. Immunophenotypic markers used for the identification and isolation of both classical $\mathrm{CD} 14^{\text {high }} / \mathrm{CD} 16^{-}$and non-classical CD16 $6^{\text {high }} / \mathrm{CD} 14^{-/ \text {low }}$ monocyte subsets.

\begin{tabular}{cccc}
\hline Marker & Fluorochrome & Clone & Source \\
\hline CD3 & APC-H7 & SK7 & BD Bioscience $^{1}$ \\
CD14 & FITC & $47-3$ D6 & Immunostep $^{2}$ \\
CD16 & PE-Cy7 & 3 G8 & BD Bioscience $^{1}$ \\
CD19 & APC & A3B1 & Immunostep $^{2}$ \\
CD33 & PerCP-Cy5.5 & P67.6 & BD Bioscience $^{1}$ \\
CD45 & PO & HI30 & Immunostep $^{2}$ \\
CD56 & PE & C5.9 & Cytognos $^{3}$ \\
HLA-DR & PB & L243 & Biolegend $^{4}$ \\
\hline
\end{tabular}

APC-H7, allophycocyanin hilite 7; FITC, fluorescein isothiocyanate; PE-Cy7, phycoerythrin cyanin 7; APC, allophycocyanin; peridinin chlorophyll protein-cyanin5.5; PO, pacific orange; PE, phycoerythrin; PB, pacific blue. ${ }^{1}$ BD Biosciences, San Diego, CA, USA; ${ }^{2}$ Immunostep SL, Salamanca, Spain; ${ }^{3}$ Cytognos SL, Salamanca, Spain;

${ }^{4}$ Biolegend, San Diego, CA, USA. 


\subsection{Cell Lysis}

Cell pellets were resuspended in lysis buffer ( $4 \%$ CHAPS $(w / v), 7 \mathrm{M}$ urea, and $2 \mathrm{M}$ thiourea) and disrupted by sonication. Cell debris were removed by centrifugation at $12,000 \mathrm{~g}$ at $4{ }^{\circ} \mathrm{C}$ for $10 \mathrm{~min}$. The supernatants were removed and their protein concentration determined by Bradford assay [23]. Samples were frozen and distributed to the different laboratories.

\subsection{Sample Processing and Mass Spectrometry Analysis}

The general procedure was as follows, $20 \mu \mathrm{g}$ of protein of each sample were fractionated in a $12 \%$ polyacrylamide SDS/PAGE. After gel staining with coomassie blue, the lanes were sliced into 10 pieces and digested following standard procedures [24]. The digestion mixture was dried in a vacuum centrifuge and resuspended in $0.1 \%$ trifluoroacetic acid. Chromatographic separation was achieved by loading tryptic peptides onto a trap column, desalted, and transferred afterwards onto an analytical column equilibrated in $2 \%$ acetonitrile $0.1 \%$ formic acid (FA). Elution was carried out with a linear gradient of $2 \%$ to $40 \%$ B (0.1\% FA in acetonitrile) in $120 \mathrm{~min}$ at a flow rate of $300 \mathrm{~nL} / \mathrm{min}$. Mass spectrometry analysis was performed with different instruments and settings (5600 TripleTOF (SCIEX, Concord, Canada), Impact QTOF (Bruker Daltonics, Bremen, Germany), and LTQ Orbitrap Velos or Q-Exactive (Thermo, Bremen, Germany), depending on the laboratory that processed the sample. The procedure performed in each laboratory may have some minor differences from the general workflow indicated above (Supplementary Table S1).

\subsection{Shotgun Data Analysis}

The datasets were analyzed following the HUPO Guidelines for the identification of proteins using MS/MS experiments. We searched all the mgf files obtained against the neXtProt database (release 20160111) [25] using the target-decoy strategy with an in-house Mascot Server v. 2.3 (Matrix Science, London, UK) search engine. Decoy database was created using the peptide pseudo-reversed method, and separate searches were performed for target and decoy databases. Search parameters were set as follows: carbamidomethyl cysteine as a fixed modification and oxidized methionine as variable modification. Precursor and fragment mass tolerance were set to $20 \mathrm{ppm}$ and $0.5 \mathrm{Da}$, respectively, and 2 missed cleavages were allowed. False Discovery Rates at PSM level and protein level using Mayu [26] were calculated, and protein identifications were obtained by applying the criteria of PSM FDR $<1 \%$ and protein FDR $<1 \%$. Protein inference was performed using the PAnalyzer algorithm [27]. Those proteins not labelled as non-conclusive by this algorithm were considered to be observed proteins in the sample.

The quantification of proteins was performed using a spectral counting approach, the normalized spectral abundance factor (NSAF) [28]. After quality assessment, a filtering process was carried out to eliminate proteins that were not identified in 7 or more samples of a cell type. To normalize each dataset, the logarithmic transformation of the NSAF were corrected by the median so that the distribution was centered around zero. In order to compare with published datasets, the NSAF values were transformed to ppm (parts per million, Table S2) as indicated by Weiss et al. [29]. Hereditary, environmental, and other factors contribute to protein abundance variability [30]. Particularly in human samples, the contribution of these factors to protein abundance is frequently larger than the biological effect under study. To overcome patient variability, we calculated the log2 CD14/CD16 ratios of the protein abundances for each patient. The median of the ratios of each patient was set to zero with the assumption that most protein abundances are essentially the same in these similar cell types [3]. This approach, however, reduces the number of data points and proteins analyzed, since each protein has to be present in both cell types of the same patient to compute the ratio, which is not always the case. To increase the number of proteins in the analysis, we performed an additional significance test comparing the average protein abundance in classical and non-classical monocytes. Proteins 
were selected as significant using a $p$-value $<0.05$ criteria in any of the two approaches using a t-test. In the first method, the significant test was applied only to proteins containing 5 or more patient ratios.

\subsection{Functional Analysis}

Functional enrichment analysis of Gene Ontology (GO) categories was carried out using DAVID [31] and STRING [32]. In the case of DAVID, the whole set of quantified proteins was used as background.

\section{Results and Discussion}

\subsection{Experimental Design}

The study of monocyte subsets is a very active research field because of their implication in many diseases. The molecular description of these cells should provide important information on their biology and function. There has been some genome-wide transcriptomics analysis $[6,13,14]$ of individual monocyte subsets, but less information at the protein level is available. Most proteomic analyses performed on monocytes have used monocyte derived cell lines or with the whole monocyte population [33-42]. Wong's group have carried out proteomic analysis on purified monocyte populations $[43,44]$, where they used iTRAQ to determine differences between cell populations. They used purified classical monocytes, but they did not purify intermediate from non-classical subsets. This mixed population is termed $\mathrm{CD}_{16}{ }^{+}$. In this scenario, and under the umbrella of the HPP, we aimed to establish a robust procedure that could be used in any proteomics laboratory to analyze monocyte subsets. Thus, a multicentric proteomic analysis of classical (CD14 ${ }^{\text {high }} / \mathrm{CD}^{-} 6^{-}$) and non-classical (CD14-/low $/$ CD16 ${ }^{\text {high }}$ ) monocyte subsets derived from 12 healthy volunteer donors was performed in five different laboratories. Our workflow consisted of a protein fractionation by SDS/PAGE followed by the LC-MS/MS shotgun analysis of 10 gel slices (Figure 1). The procedure provides a good compromise between proteome coverage and throughput that could be considered to be a useful proteomic tool for studying and comparing the proteome profile of monocyte subsets under different physiological and pathological conditions. Inter-laboratory experiments are very useful, because they allow the evaluation of the robustness of proteomic workflows. In this context, our results indicate that, despite the number of individuals and laboratories participating in the study, the procedure is quite reproducible. The number of identified proteins ranged from about 3600 to 4800 proteins in the five participating laboratories (Figure 2A), with more than 2600 of them found in all laboratories (Figure 2B). Virtually the same number of proteins were identified in each cell type with more that $85 \%$ overlap (Figure $2 \mathrm{C}$ ). The identified proteins are evenly distributed among chromosomes with an average chromosome coverage of about 30\% (Figure 2D), and without any significant difference in chromosome coverage between cell types. Only Y chromosome and mitochondrial DNA, which have a small number of proteins, showed extreme coverage values. According to neXtprot database, 111 of the identified proteins should be classified as missing proteins, since they are within the protein evidence categories 2 and 3 (Figure 2D). However, further investigation will be necessary to confirm these missing proteins.

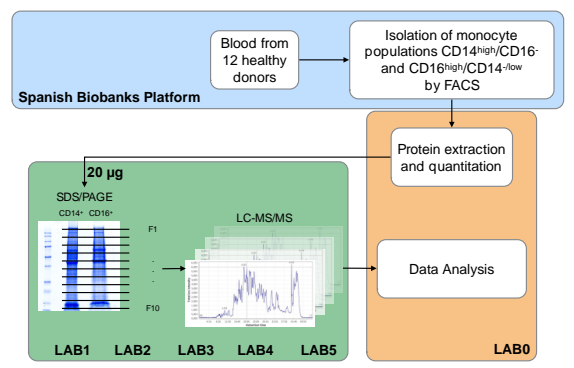

Figure 1. Scheme of the experimental strategy. 


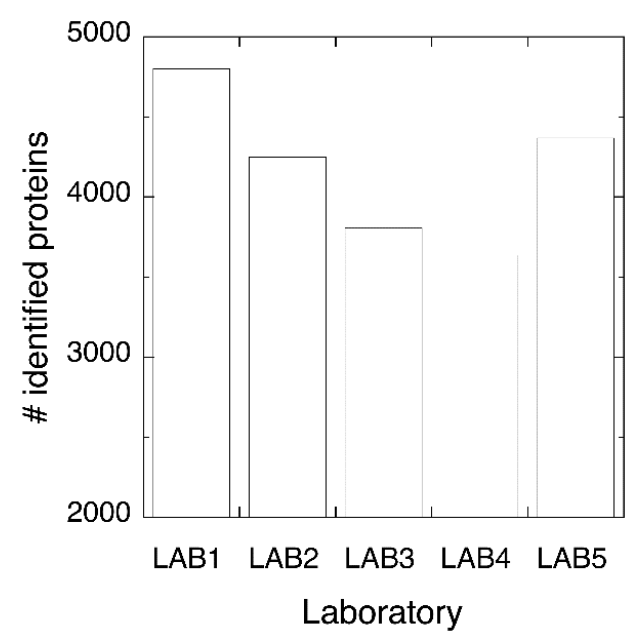

(A)

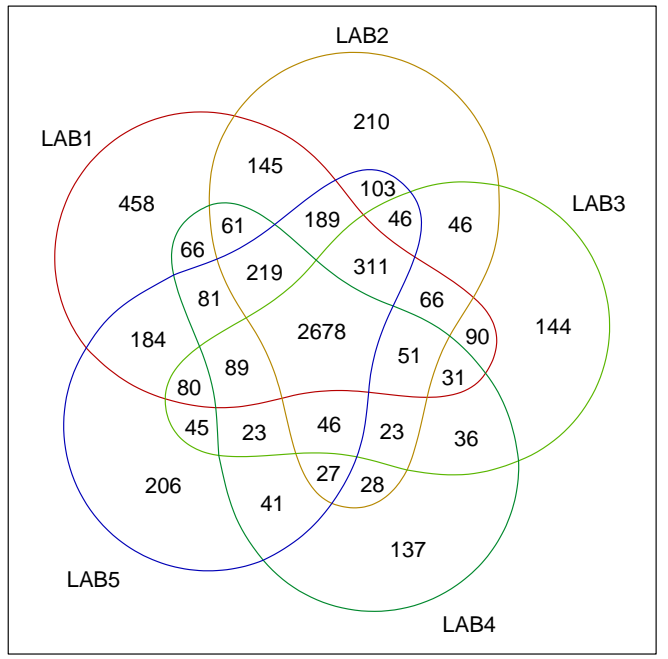

(B)

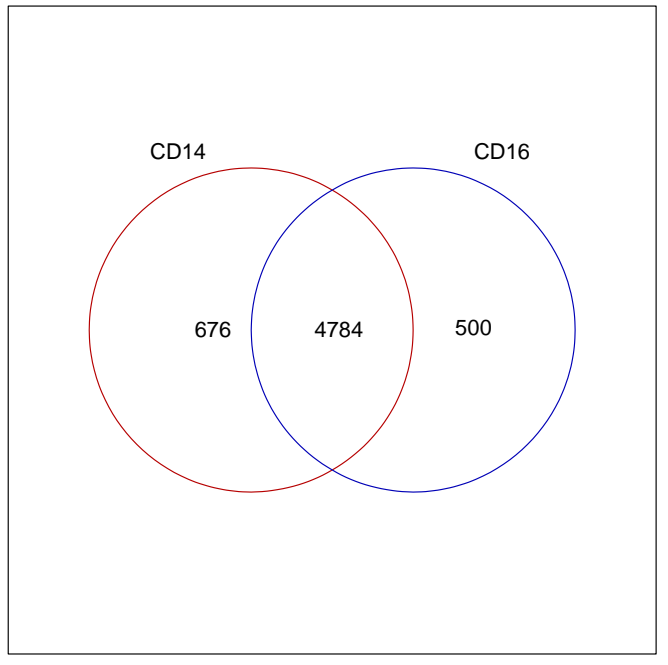

(C)

Figure 2. Cont. 


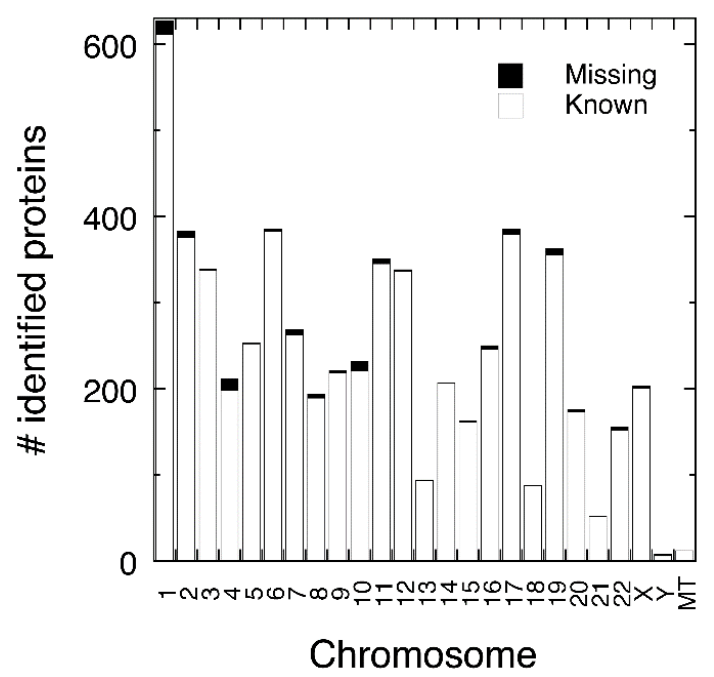

(D)

Figure 2. (A) Number of total proteins identified in each participating laboratory; (B) Venn diagram showing the overlap of the identified proteins among laboratories; (C) Venn diagram of identified proteins grouped by cell type; (D) Number of identified proteins grouped by chromosome. Missing proteins, according to NeXtprot database criteria, are indicated in black.

\subsection{Protein Abundance}

Protein abundance was estimated by a spectral counting approach; the normalized spectral abundance factor (NSAF). Quantitative methods based in spectral counting are less accurate than other alternatives, such as intensity-based alternatives. However, its simplicity, even with fractionated samples, makes it a very convenient quantitative tool for routinely providing quantitative data. Even in biomarker discovery experiments in a clinical context, where comparison of many samples was necessary, spectral counting quantitation is a valid option [45]. Our NSAF data produced consistent data distribution along samples and laboratories (Figures S1 and S2). After filtering out the low-expression proteins, almost 2600 could be quantitated, and almost all of them (93\%) in all five laboratories. The results showed a good correlation among all datasets (Table S4), with a median Pearson correlation coefficient of 0.80 (ranging from 0.66 to 0.93). As expected, the correlation within laboratories was slightly higher (average correlation 0.85 ) than between laboratories (average correlation 0.79 ). This degree of reproducibility between laboratories is comparable with results obtained in other multi-laboratory experiments using a more accurate quantitative approach such as SRM [46], indicating the robustness of the experimental procedure. We have estimated that, from $20 \mu \mathrm{g}$ of starting protein amount, our limit of detection and quantitation is about 20 and $120 \mathrm{pg}$ of protein, respectively. Since previous studies with purified cells used a relative quantitative approach [43,44], this is the first partial protein abundance catalogue of purified classical and non-classical monocyte subsets. There is a good correlation between the protein abundances of classical and non-classical monocyte with the dataset of the complete monocyte population [33] obtained from PaxDb [47] (Figure 3). On the contrary, there is no correlation with a liver dataset, underscoring the significance of the NSAF quantitative data. The observed reproducibility suggests that these datasets could be used as a healthy monocyte reference for comparison with monocytes obtained from different physiological or pathological conditions. 


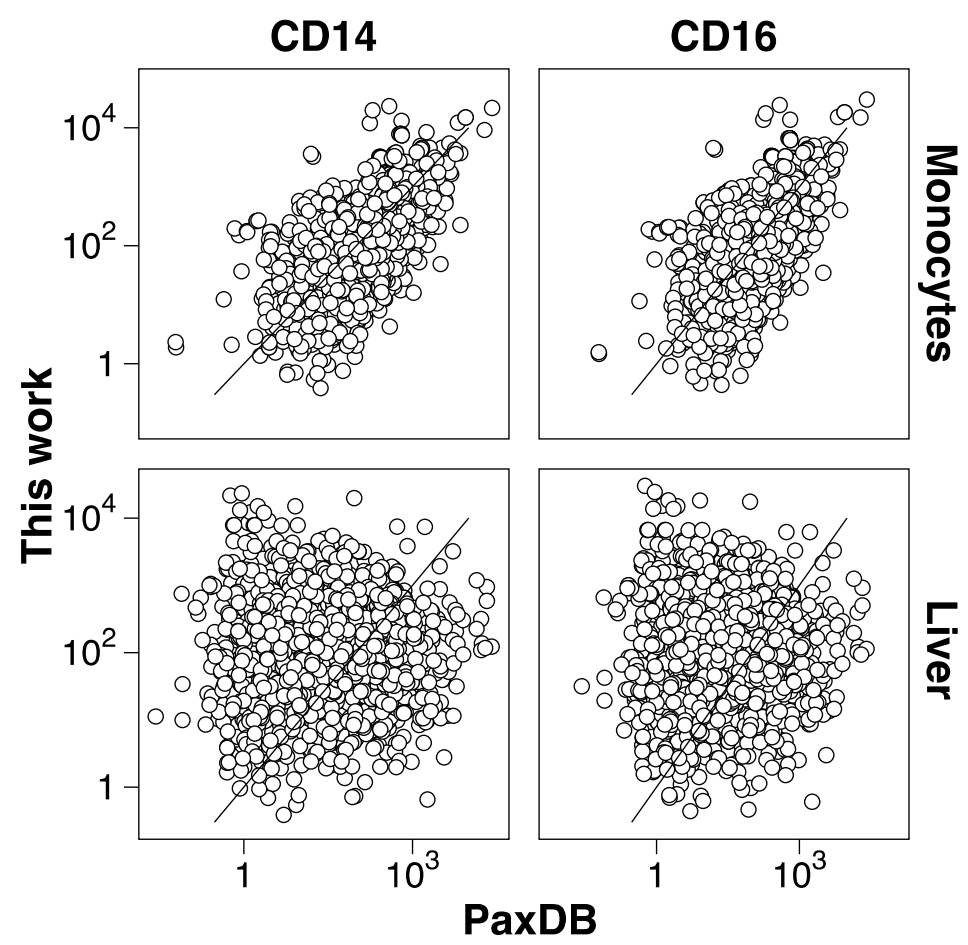

Figure 3. Protein abundance correlation between purified monocyte populations and public datasets obtained from PaxDB. Protein abundances determined in the present work (y-axis) are plotted against public datasets (x-axis). CD14 (classical) and CD16 (non-classical), are shown in left and right panels, respectively. Complete monocyte population and liver datasets are shown in the top panels and bottom panels, respectively.

About 100 proteins were differentially expressed—nearly half of them overexpressed-in each cell type. This number is lower than what was observed in an iTRAQ analysis [44]. Although the purities of the $\mathrm{CD}_{16}{ }^{+}$populations used are different, the main difference probably resides in the larger variability of our experimental setup. The inter-individual and inter-laboratory variability introduced in our experimental design certainly increases the magnitude of the biological change required to be detected. Indeed, a considerable inter-individual variability was also observed in a transcriptomic analysis of pure monocyte subsets [6]. In addition, spectral counting quantitative accuracy is lower than ITRAQ. Our experiment was intended to reproduce the working conditions expected to operate in collaborative projects such as the HPP. Thus, the fact that differentially expressed proteins could be detected under these experimental conditions underscores the usefulness of these type of experiments.

\subsection{Functional Analysis}

The functional analysis of the differentially expressed proteins indicates that they are biologically related (Figure 4). The biological processes in which differential proteins are involved support the consensus functions assigned to these cell types [5] and reviewed in [10,11]. Non-classical monocytes have been proposed to have an important role in anti-viral immunity, which is mediated by TLR $7 / 8$ receptors. They have also been assigned a patrolling function, and proposed to induce $T$ cell proliferation and activation. Indeed, the abundance of some of the proteins involved in these processed were observed to increase in the non-classical subset (Figure 4B). In accordance with these functions, some of the GO terms enriched in these cells are related to the immune system response (Supplementary Tables S6 and S7). It is interesting to note that integral membrane proteins are also enriched (Supplementary Tables S6 and S7). This result is, at least in part, due to the fact that most of the identified protein related to immune system responses are membrane proteins. Frequently, 
membrane proteins are underrepresented in proteomic experiments; probably because of their low solubility. Thus, the enrichment of membrane proteins in this fraction is an unexpected result. The use of an SDS/PAGE step to fractionate proteins may have contributed to overcome the low solubility of membrane proteins and allow their enrichment. This is particularly useful for studying the biology of monocyte populations, since membrane proteins are the main determinants for their classification, purification and manipulation.

The main function of the classical subset is phagocytosis. Phagocytosis and ROS production, both of which are reduced in non-classical monocytes [5], are associated with a metabolic reprogramming. In macrophages $\mathrm{M} 1$, which are derived from classical monocytes, a switch from oxidative phosphorylation to glycolysis has been described [48]. This is like the Warburg effect observed in proliferating tumor cells, although, in this case, the high glycolytic flux is not required for proliferation, but for ROS production. The increase in glycolysis also produces increases in the pentose phosphate pathway and nucleotide metabolism, which are needed for the production of NADPH used to produce ROS. Supporting this metabolic switch, among the proteins with increased abundance, those involved in nucleotide and glucose metabolism are significantly enriched (Figure 4A, and Supplementary Tables S6 and S7).

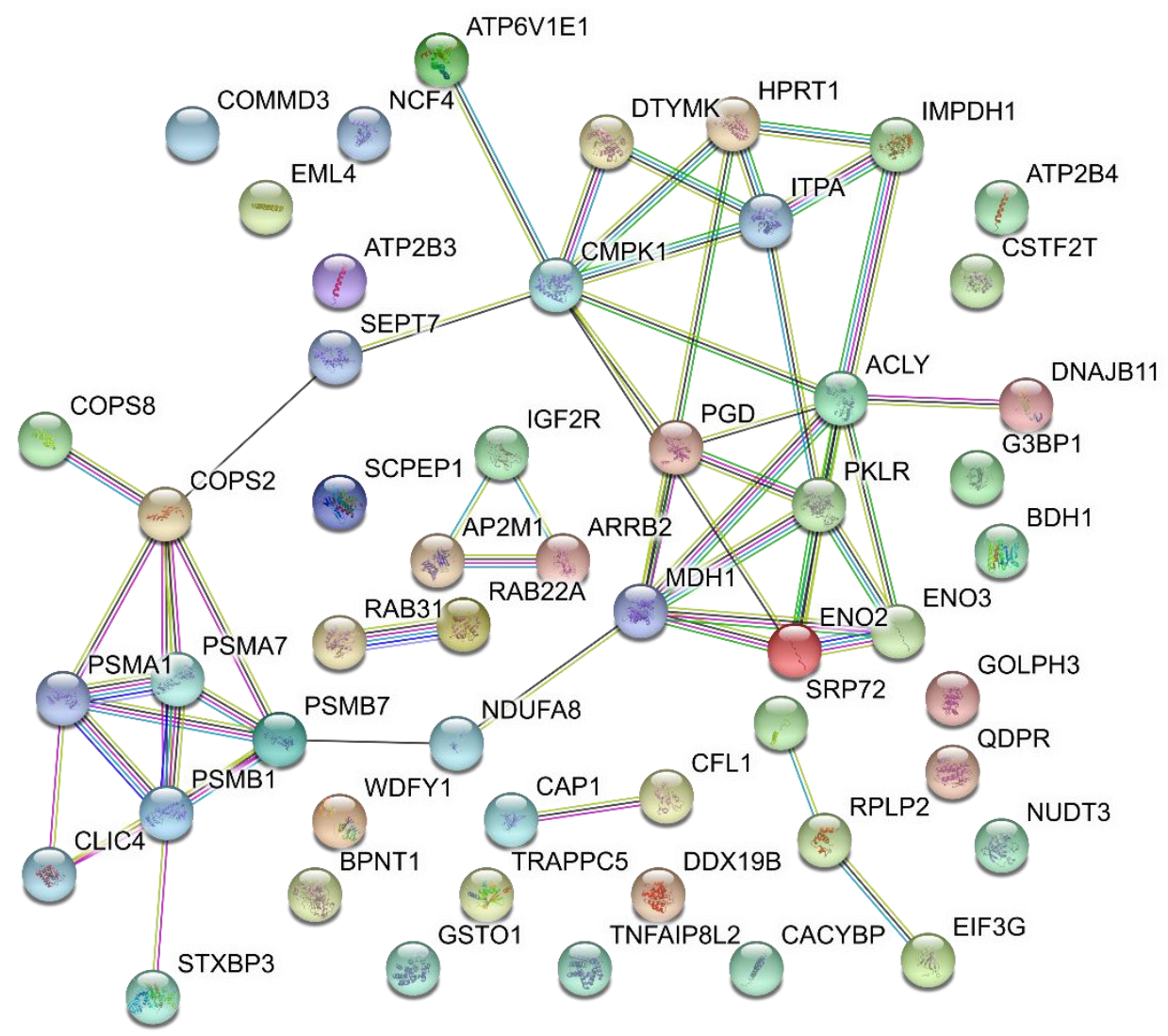

(A)

Figure 4. Cont. 


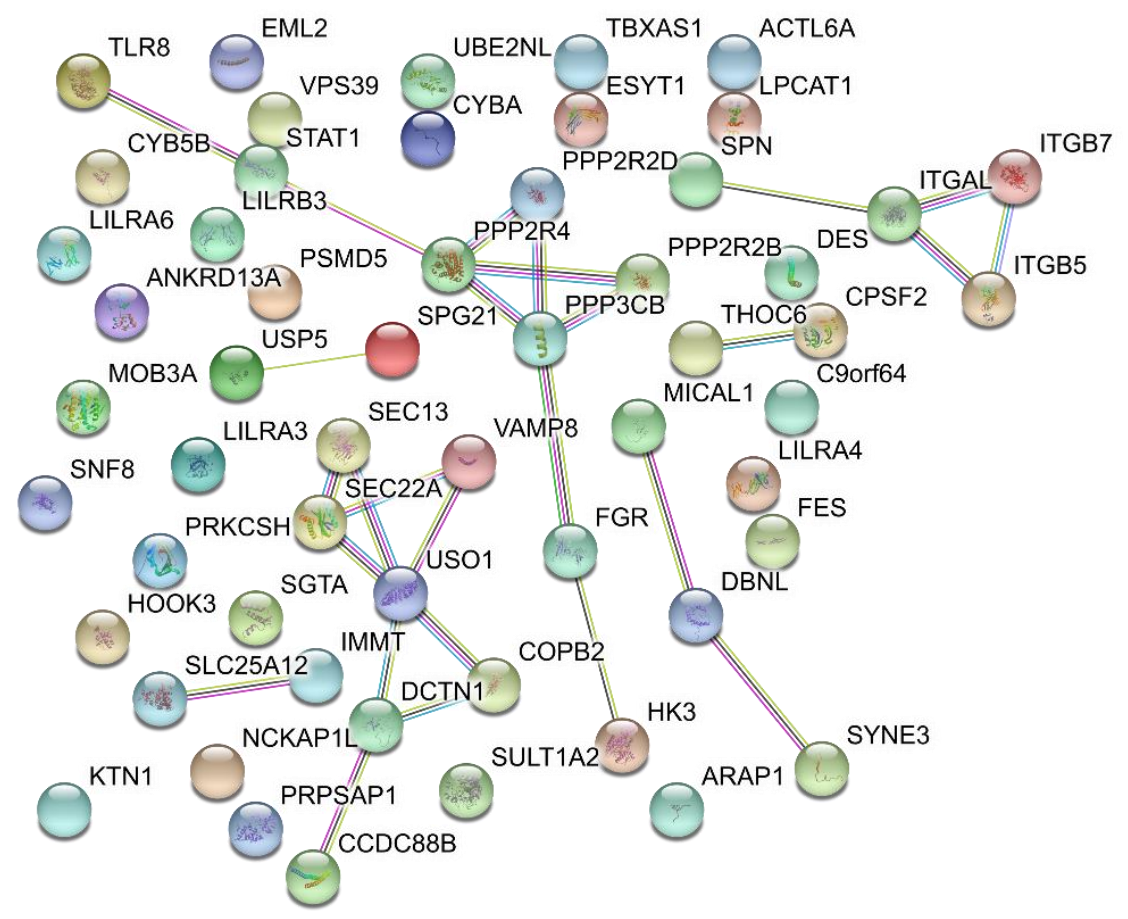

(B)

Figure 4. STRING analysis. (A) Increased abundance proteins in classical monocytes; (B) Increased abundance proteins in non-classical monocytes. STRING color code for interacting lines: cyan: curated databases; magenta: experimentally determined; green: gene neighborhood; red: gene fusions; blue: gene co-occurrence; golden: textmining; black: co-expression; purple: protein homology.

\section{Conclusions}

We have performed a multicentric proteomic characterization of the classical and non-classical monocyte populations using a relatively simple experimental approach. The high reproducibility of the results obtained in different laboratories demonstrated the robustness of the procedure. The obtained results constitute the first protein abundance catalogue of pure classical and non-classical monocyte populations and its functional analysis supports the established functions of these cell types. The results can be a useful proteomic tool for the study of the biology of monocytes in different pathological conditions serving as a reference set of healthy individuals.

Supplementary Materials: The following are available online at www.mdpi.com/2227-7382/6/1/8/s1, Figure S1: Box Plot of the $\log (\mathrm{NSAF})$ of identified proteins, Figure S2: Box Plot of the $\log (\mathrm{NSAF} / \mathrm{Med})$ of quantified proteins, Table S1: Details of the sample processing and mass spectrometry used in each laboratory, Table S2: Identified proteins, Table S3: Quantified proteins, Table S4: Correlation analysis of all quantitation datasets, Table S5: Differential proteins, Table S6: Functional enrichment results from STRING, and Table S7: Functional enrichment results from DAVID.

Acknowledgments: All participating laboratories are members of the PRBB-ISCIII platform. This work was supported by the Carlos III Health Institute of Spain (ISCIII, FIS PI11/02114 and FIS PI14/01538)-Fondos FEDER (EU); grants SAF2014-5478-R from Ministerio de Economía y Competitividad to FJC; grant DPI2015-68982-R from Ministerio de Ciencia e Innovación to VS; P.D. is supported by a JCYL-EDU/346/2013 Ph.D. scholarship.

Author Contributions: M.L.V, L.C., E.Z., F.G., K.A., J.B., R.N., A.P., P.D. and R.M ${ }^{a}$.D. performed the experiments; J.M., J.M.A., M.F., A.O., A.G.M., F.J.C. and M.M.S.d.P. conceived and designed the experiments; V.S., A.G., and M.M.S.d.P. analyzed the data; and M.M.S.d.P. wrote the paper.

Conflicts of Interest: The authors declare no conflict of interest. 


\section{References}

1. Van Furth, R.; Cohn, Z.A. The origin and kinetics of mononuclear phagocytes. J. Exp. Med. 1968, 128, 415-435. [CrossRef] [PubMed]

2. Passlick, B.; Flieger, D.; Ziegler-Heitbrock, H.W. Identification and characterization of a novel monocyte subpopulation in human peripheral blood. Blood 1989, 74, 2527-2534. [PubMed]

3. Ziegler-Heitbrock, L.; Ancuta, P.; Crowe, S.; Dalod, M.; Grau, V.; Hart, D.N.; Leenen, P.J.; Liu, Y.J.; MacPherson, G.; Randolph, G.J.; et al. Nomenclature of monocytes and dendritic cells in blood. Blood 2010, 116, e74-e80. [CrossRef] [PubMed]

4. Belge, K.U.; Dayyani, F.; Horelt, A.; Siedlar, M.; Frankenberger, M.; Frankenberger, B.; Espevik, T.; Ziegler-Heitbrock, L. The proinflammatory CD14+CD16+DR++ monocytes are a major source of TNF. J. Immunol. 2002, 168, 3536-3542. [CrossRef] [PubMed]

5. Cros, J.; Cagnard, N.; Woollard, K.; Patey, N.; Zhang, S.Y.; Senechal, B.; Puel, A.; Biswas, S.K.; Moshous, D.; Picard, C.; et al. Human CD14dim monocytes patrol and sense nucleic acids and viruses via TLR7 and TLR8 receptors. Immunity 2010, 33, 375-386. [CrossRef] [PubMed]

6. Wong, K.L.; Tai, J.J.; Wong, W.C.; Han, H.; Sem, X.; Yeap, W.H.; Kourilsky, P.; Wong, S.C. Gene expression profiling reveals the defining features of the classical, intermediate, and nonclassical human monocyte subsets. Blood 2011, 118, e16-e31. [CrossRef] [PubMed]

7. Fingerle, G.; Pforte, A.; Passlick, B.; Blumenstein, M.; Strobel, M.; Ziegler-Heitbrock, H.W. The novel subset of CD14+/CD16+ blood monocytes is expanded in sepsis patients. Blood 1993, 82, 3170-3176. [PubMed]

8. Grip, O.; Bredberg, A.; Lindgren, S.; Henriksson, G. Increased subpopulations of CD16(+) and CD56(+) blood monocytes in patients with active Crohn's disease. Inflamm. Bowel Dis. 2007, 13, 566-572. [CrossRef] [PubMed]

9. Ziegler-Heitbrock, H.W. Heterogeneity of human blood monocytes: The CD14+ CD16+ subpopulation. Immunol. Today 1996, 17, 424-428. [CrossRef]

10. Wong, K.L.; Yeap, W.H.; Tai, J.J.; Ong, S.M.; Dang, T.M.; Wong, S.C. The three human monocyte subsets: Implications for health and disease. Immunol. Res. 2012, 53, 41-57. [CrossRef] [PubMed]

11. Yang, J.; Zhang, L.; Yu, C.; Yang, X.F.; Wang, H. Monocyte and macrophage differentiation: Circulation inflammatory monocyte as biomarker for inflammatory diseases. Biomark. Res. 2014, 2, 1. [CrossRef] [PubMed]

12. Fingerle-Rowson, G.; Auers, J.; Kreuzer, E.; Fraunberger, P.; Blumenstein, M.; Ziegler-Heitbrock, L.H. Expansion of CD14+CD16+ monocytes in critically ill cardiac surgery patients. Inflammation 1998, 22, 367-379. [CrossRef] [PubMed]

13. Zawada, A.M.; Rogacev, K.S.; Rotter, B.; Winter, P.; Marell, R.R.; Fliser, D.; Heine, G.H. SuperSAGE evidence for CD14++CD16+ monocytes as a third monocyte subset. Blood 2011, 118, e50-e61. [CrossRef] [PubMed]

14. Anbazhagan, K.; Duroux-Richard, I.; Jorgensen, C.; Apparailly, F. Transcriptomic network support distinct roles of classical and non-classical monocytes in human. Int. Rev. Immunol. 2014, 33, 470-489. [CrossRef] [PubMed]

15. Weiner, L.M.; Li, W.; Holmes, M.; Catalano, R.B.; Dovnarsky, M.; Padavic, K.; Alpaugh, R.K. Phase I trial of recombinant macrophage colony-stimulating factor and recombinant gamma-interferon: Toxicity, monocytosis, and clinical effects. Cancer Res. 1994, 54, 4084-4090. [PubMed]

16. Archakov, A.; Zgoda, V.; Kopylov, A.; Naryzhny, S.; Chernobrovkin, A.; Ponomarenko, E.; Lisitsa, A. Chromosome-centric approach to overcoming bottlenecks in the Human Proteome Project. Expert Rev. Proteom. 2012, 9, 667-676. [CrossRef] [PubMed]

17. Legrain, P.; Aebersold, R.; Archakov, A.; Bairoch, A.; Bala, K.; Beretta, L.; Bergeron, J.; Borchers, C.H.; Corthals, G.L.; Costello, C.E.; et al. The human proteome project: Current state and future direction. Mol. Cell. Proteom. 2011, 10, M111.009993. [CrossRef] [PubMed]

18. Omenn, G.S. The strategy, organization, and progress of the HUPO Human Proteome Project. J. Proteom. 2014, 100, 3-7. [CrossRef] [PubMed]

19. Paik, Y.K.; Jeong, S.K.; Omenn, G.S.; Uhlen, M.; Hanash, S.; Cho, S.Y.; Lee, H.J.; Na, K.; Choi, E.Y.; Yan, F.; et al. The Chromosome-Centric Human Proteome Project for cataloging proteins encoded in the genome. Nat. Biotechnol. 2012, 30, 221-223. [CrossRef] [PubMed] 
20. Paik, Y.K.; Omenn, G.S.; Uhlen, M.; Hanash, S.; Marko-Varga, G.; Aebersold, R.; Bairoch, A.; Yamamoto, T.; Legrain, P.; Lee, H.J.; et al. Standard guidelines for the chromosome-centric human proteome project. J. Proteome Res. 2012, 11, 2005-2013. [CrossRef] [PubMed]

21. Cantor, D.I.; Nice, E.C.; Baker, M.S. Recent findings from the Human Proteome Project: Opening the mass spectrometry toolbox to advance cancer diagnosis, surveillance and treatment. Expert Rev. Proteom. 2015, 12, 279-293. [CrossRef] [PubMed]

22. Almeida, J.; Bueno, C.; Alguero, M.C.; Sanchez, M.L.; de Santiago, M.; Escribano, L.; Diaz-Agustin, B.; Vaquero, J.M.; Laso, F.J.; San Miguel, J.F.; et al. Comparative analysis of the morphological, cytochemical, immunophenotypical, and functional characteristics of normal human peripheral blood lineage(-)/CD16(+)/HLA-DR(+)/CD14(-/lo) cells, CD14(+) monocytes, and CD16(-) dendritic cells. Clin. Immunol. 2001, 100, 325-338. [CrossRef] [PubMed]

23. Zor, T.; Selinger, Z. Linearization of the Bradford protein assay increases its sensitivity: Theoretical and experimental studies. Anal. Biochem. 1996, 236, 302-308. [CrossRef] [PubMed]

24. Shevchenko, A.; Jensen, O.N.; Podtelejnikov, A.V.; Sagliocco, F.; Wilm, M.; Vorm, O.; Mortensen, P.; Shevchenko, A.; Boucherie, H.; Mann, M. Linking genome and proteome by mass spectrometry: Large-scale identification of yeast proteins from two dimensional gels. Proc. Natl. Acad. Sci. USA 1996, 93, 14440-14445. [CrossRef] [PubMed]

25. Lane, L.; Argoud-Puy, G.; Britan, A.; Cusin, I.; Duek, P.D.; Evalet, O.; Gateau, A.; Gaudet, P.; Gleizes, A.; Masselot, A.; et al. neXtProt: A knowledge platform for human proteins. Nucleic Acids Res. 2012, 40, D76-D83. [CrossRef] [PubMed]

26. Reiter, L.; Claassen, M.; Schrimpf, S.P.; Jovanovic, M.; Schmidt, A.; Buhmann, J.M.; Hengartner, M.O.; Aebersold, R. Protein identification false discovery rates for very large proteomics data sets generated by tandem mass spectrometry. Mol. Cell. Proteom. 2009, 8, 2405-2417. [CrossRef] [PubMed]

27. Prieto, G.; Aloria, K.; Osinalde, N.; Fullaondo, A.; Arizmendi, J.M.; Matthiesen, R. PAnalyzer: A software tool for protein inference in shotgun proteomics. BMC Bioinf. 2012, 13, 288. [CrossRef] [PubMed]

28. Paoletti, A.C.; Parmely, T.J.; Tomomori-Sato, C.; Sato, S.; Zhu, D.; Conaway, R.C.; Conaway, J.W.; Florens, L.; Washburn, M.P. Quantitative proteomic analysis of distinct mammalian Mediator complexes using normalized spectral abundance factors. Proc. Natl. Acad. Sci. USA 2006, 103, 18928-18933. [CrossRef] [PubMed]

29. Weiss, M.; Schrimpf, S.; Hengartner, M.O.; Lercher, M.J.; von Mering, C. Shotgun proteomics data from multiple organisms reveals remarkable quantitative conservation of the eukaryotic core proteome. Proteomics 2010, 10, 1297-1306. [CrossRef] [PubMed]

30. Liu, Y.; Buil, A.; Collins, B.C.; Gillet, L.C.; Blum, L.C.; Cheng, L.Y.; Vitek, O.; Mouritsen, J.; Lachance, G.; Spector, T.D.; et al. Quantitative variability of 342 plasma proteins in a human twin population. Mol. Syst. Biol. 2015, 11, 786. [CrossRef] [PubMed]

31. Huang da, W.; Sherman, B.T.; Lempicki, R.A. Systematic and integrative analysis of large gene lists using DAVID bioinformatics resources. Nat. Protoc. 2009, 4, 44-57. [CrossRef] [PubMed]

32. Szklarczyk, D.; Franceschini, A.; Wyder, S.; Forslund, K.; Heller, D.; Huerta-Cepas, J.; Simonovic, M.; Roth, A.; Santos, A.; Tsafou, K.P.; et al. STRING v10: Protein-protein interaction networks, integrated over the tree of life. Nucleic Acids Res. 2015, 43, D447-D452. [CrossRef] [PubMed]

33. Kim, M.-S.; Pinto, S.M.; Getnet, D.; Nirujogi, R.S.; Manda, S.S.; Chaerkady, R.; Madugundu, A.K.; Kelkar, D.S.; Isserlin, R.; Jain, S.; et al. A draft map of the human proteome. Nature 2014, 509, 575-581. [CrossRef] [PubMed]

34. Barderas, M.G.; Tunon, J.; Darde, V.M.; De la Cuesta, F.; Duran, M.C.; Jimenez-Nacher, J.J.; Tarin, N.; Lopez-Bescos, L.; Egido, J.; Vivanco, F. Circulating human monocytes in the acute coronary syndrome express a characteristic proteomic profile. J. Proteome Res. 2007, 6, 876-886. [CrossRef] [PubMed]

35. Daswani, B.; Gupta, M.K.; Gavali, S.; Desai, M.; Sathe, G.J.; Patil, A.; Parte, P.; Sirdeshmukh, R.; Khatkhatay, M.I. Monocyte Proteomics Reveals Involvement of Phosphorylated HSP27 in the Pathogenesis of Osteoporosis. Dis. Markers 2015, 2015, 196589. [CrossRef] [PubMed]

36. Pabst, M.J.; Pabst, K.M.; Handsman, D.B.; Beranova-Giorgianni, S.; Giorgianni, F. Proteome of monocyte priming by lipopolysaccharide, including changes in interleukin-1beta and leukocyte elastase inhibitor. Proteome Sci. 2008, 6, 13. [CrossRef] [PubMed] 
37. Polati, R.; Castagna, A.; Bossi, A.; Campostrini, N.; Zaninotto, F.; Timperio, A.M.; Zolla, L.; Olivieri, O.; Corrocher, R.; Girelli, D. High resolution preparation of monocyte-derived macrophages (MDM) protein fractions for clinical proteomics. Proteome Sci. 2009, 7, 4. [CrossRef] [PubMed]

38. Tarasova, N.K.; Ytterberg, A.J.; Lundberg, K.; Zhang, X.M.; Harris, R.A.; Zubarev, R.A. Proteomics Reveals a Role for Attachment in Monocyte Differentiation into Efficient Proinflammatory Macrophages. J. Proteome Res. 2015, 14, 3940-3947. [CrossRef] [PubMed]

39. Tarasova, N.K.; Ytterberg, A.J.; Lundberg, K.; Zhang, X.M.; Harris, R.A.; Zubarev, R.A. Establishing a Proteomics-Based Monocyte Assay To Assess Differential Innate Immune Activation Responses. J. Proteome Res. 2016, 15, 2337-2345. [CrossRef] [PubMed]

40. Eligini, S.; Brioschi, M.; Fiorelli, S.; Tremoli, E.; Banfi, C.; Colli, S. Human monocyte-derived macrophages are heterogenous: Proteomic profile of different phenotypes. J. Proteom. 2015, 124, 112-123. [CrossRef] [PubMed]

41. Shipman, M.; Lubick, K.; Fouchard, D.; Guram, R.; Grieco, P.; Jutila, M.; Dratz, E.A. Proteomic and systems biology analysis of monocytes exposed to securinine, a GABA(A) receptor antagonist and immune adjuvant. PLoS ONE 2012, 7, e41278. [CrossRef] [PubMed]

42. Maes, E.; Landuyt, B.; Mertens, I.; Schoofs, L. Interindividual variation in the proteome of human peripheral blood mononuclear cells. PLoS ONE 2013, 8, e61933. [CrossRef] [PubMed]

43. Zhao, C.; Tan, Y.C.; Wong, W.C.; Sem, X.; Zhang, H.; Han, H.; Ong, S.M.; Wong, K.L.; Yeap, W.H.; Sze, S.K.; et al. The CD14(+/low)CD16(+) monocyte subset is more susceptible to spontaneous and oxidant-induced apoptosis than the CD14(+)CD16(-) subset. Cell Death Dis. 2010, 1, e95. [CrossRef] [PubMed]

44. Zhao, C.; Zhang, H.; Wong, W.C.; Sem, X.; Han, H.; Ong, S.M.; Tan, Y.C.; Yeap, W.H.; Gan, C.S.; Ng, K.Q.; et al. Identification of novel functional differences in monocyte subsets using proteomic and transcriptomic methods. J. Proteome Res. 2009, 8, 4028-4038. [CrossRef] [PubMed]

45. Bosch, L.J.W.; de Wit, M.; Pham, T.V.; Coupé, V.M.H.; Hiemstra, A.C.; Piersma, S.R.; Oudgenoeg, G.; Scheffer, G.L.; Mongera, S.; Sive Droste, J.T.; et al. Novel Stool-Based Protein Biomarkers for Improved Colorectal Cancer Screening: A Case-Control Study. Ann. Intern. Med. 2017, 167, 855-866. [CrossRef] [PubMed]

46. Wegler, C.; Gaugaz, F.Z.; Andersson, T.B.; Wisniewski, J.R.; Busch, D.; Gröer, C.; Oswald, S.; Norén, A.; Weiss, F.; Hammer, H.S.; et al. Variability in Mass Spectrometry-based Quantification of Clinically Relevant Drug Transporters and Drug Metabolizing Enzymes. Mol. Pharm. 2017, 14, 3142-3151. [CrossRef] [PubMed]

47. Wang, M.; Weiss, M.; Simonovic, M.; Haertinger, G.; Schrimpf, S.P.; Hengartner, M.O.; von Mering, C. PaxDb, a database of protein abundance averages across all three domains of life. Mol. Cell. Proteom. 2012, 11, 492-500. [CrossRef] [PubMed]

48. Kelly, B.; O'Neill, L.A. Metabolic reprogramming in macrophages and dendritic cells in innate immunity. Cell Res. 2015, 25, 771-784. [CrossRef] [PubMed]

(C) 2018 by the authors. Licensee MDPI, Basel, Switzerland. This article is an open access article distributed under the terms and conditions of the Creative Commons Attribution (CC BY) license (http://creativecommons.org/licenses/by/4.0/). 